\title{
Novel Medicine: Cancer Ward, Alexander Solzhenitsyn
}

\author{
A Mark Clarfield
}

J R Soc Med 2006;99:641

I read Cancer Ward thirty years ago. About to enter medicine, I found the book's clinical aspects exciting, although I was not yet able to interpret it with the eye of a practicing physician. On re-reading it recently, the novel's magic remains. The book's literary device is simple but clever, offering a mirror of Soviet society-especially around one of the 'cultural thaws' which the USSR repeatedly experienced.

'One of the sub-themes involves changing weather: premature spring thaws are followed by cold spells with everything freezing over again. These natural phenomena stand as a metaphor for the unnatural decisions of the powers that thaw and freeze political freedom. It is not only the weather which is a powerful symbol, but the practice of medicine which Solzhenitsyn compares to the USSR's political culture.

Diverse characters, put together in the oncology ward of a provincial hospital, have two things in common: they all suffer from a malignancy and all are citizens of the great USSR, which is going through the momentous changes of de-Stalinization. However, here is where all similarities break down. Each patient has his own political/historical background which Solzhenitsyn uses to relate to Soviet history - both past and contemporary.

Kostoglotov and Rusanov are two major characters; the former a distinguished soldier expelled to the Gulag immediately the war ended, the latter is a party functionary who comfortably spent the war as a 'manpower manager', heroically informing on his fellow citizens. Both suffer from cancer and both are cured by a combination of heavy-duty radiotherapy and injections (presumably hormonal therapy) which threaten their potency and, as such, their masculinity.

Although most of the doctors come off well (the exception is the 'Chief Doctor', who enjoys more privileges than medical abilities), Solzhenitsyn makes much out of ironically comparing the ward to a prison. While the subjects, prisoner or patient, are promised many rights in theory, they enjoy almost none in practice.

For their part, while the patients are lied to by the clinical staff 'for their own good', in theory they may refuse therapy. Of course, given the alternatives presented (or implied), they end up almost always 'agreeing' to

Department of Geriatrics, Soroka Hospital, Ben-Gurion University of the Negev, P.O. Box 151, Beer-Sheva 84101, Israel; and Division of Geriatric Medicine, Sir Mortimer B Davis - Jewish, General Hospital, McGill University, Montreal, Canada

E-mail: markclar@bgu.ac.il treatment. The prisoner is presented as a distorted mirror image of the patient. Even in Stalin's Gulag there was a pretense of 'correcting' the inmates. Prisoners, while cruelly abused, were allowed to write 'official complaints'. Of course, these letters were ignored by the authorities.

The brave soldier Kostoglotov compares the present hospital environment with his recent camp experiences. In a letter to friends (page 291), he offers a riddle:

'Here's a puzzle picture for you: what is it and where am I? Bars on the windows (only on the first floor, it is true, to keep the burglars out, and they are in a geometric pattern like rays of light . . . and there are no shields to bar the view either). The rooms are full of bunks . . . and on each bunk lies a little man terrified out of his wits.

In the morning you get a bread roll, sugar and tea (this is a breach of regulations, because they give you breakfast later on). All through the morning people are gloomy and silent . . . but in the evenings there is a constant hum and lively discussion: about opening and closing windows, about who can hope for the best and who can expect the worst, and about how many bricks there are in the mosque at Samarkand . . .

Well, have you guessed? Of course you'll say I must be lying: if it's a transit prison, why the bedclothes? And if it's a prison, why are there no night-time interrogations?'

A secondary theme, more medical, involves the ongoing conflict between conventional and alternative medicine. Another letter from Kostoglotov (page 296):

'When I get back to Ush-Terek [his place of exile], I'll give my tumor another pummeling with that mandrake root . . . just to make sure it doesn't start throwing secondaries about. There's something noble about treating oneself with a strong poison. Poison doesn't pretend to be a harmless medicine, it tells you straight out, "I'm poison! Watch out! Or else!" So we know what we're in for.'

Over the years in Israel, I have had the opportunity to work with many physicians and nurses of Russian origin. At times I found myself somewhat perplexed by their clinical reflexes and choices. This book has helped me to better understand my colleagues. Cancer Ward offers insights into both politics and medicine, as well as into the politics of medicine. Solzhenitsyn also has much to teach us about clinical practice and respect for patients. 